\title{
Arghhhhh!!! Eu nunca mais vou comer pimenta... Oba! Pimenta! Homer Simpson, arquitetura de escolha e politicas públicas
}

Daniela Goya Tocchetto*

Sabino da Silva Porto Júnior ${ }^{* *}$

RESUMO - Esse artigo apresenta uma breve introdução à discussão sobre Nudge e arquitetura de escolha, como uma nova alternativa de desenhar políticas públicas. O principal objetivo é melhor compreender a natureza do nudge e apontar as suas possíveis aplicações. Por fim, comentamos rapidamente algumas de suas implicações éticas.

Palavras-chave: Arquitetura de escolha. Nudge. Políticas públicas.

\section{INTRODUÇÃO}

Se fôssemos todos homo economicus, viveríamos no melhor dos mundos possíveis. No entanto, nós somos mais próximos de algo como um Homer economicus ${ }^{1}$ (THALER e SUNSTEIN, 2009). Logo, podemos melhorar o nosso mundo e torná-lo um lugar mais simples para nós, humanos imperfeitos, vivermos. Esse é o apelo de $n u d g e^{2}$ : o que Thaler e Sunstein chamam também de Paternalismo Libertário; a verdadeira alternativa entre o paternalismo e o libertarianismo na formulação de políticas públicas.

Nudge é uma maneira de formular políticas públicas através do desenho de uma arquitetura de escolha que objetiva conduzir propositalmente as decisões dos indivíduos em direções que são ou do seu melhor interesse ou do melhor interesse da sociedade, sempre mantendo a liberdade de escolha através da presença, no conjunto de possibilidades, de alternativas de escolhas variadas para os indivíduos. Essa ideia, conhecida como Paternalismo Libertário, está baseada nos resultados empíricos encontrados tanto pela economia experimental quanto pela psicologia experimental, que revelam diversos padrões de erros nos processos de tomada de decisão humanos. O que ensejaria espaço para uma atuação efetiva na arquitetura de escolha propiciando aos indivíduos um desenho capaz de induzir ganhos de bem-estar.

Thaler e Sunstein (2009) apresentam dois exemplos simples que ilustram melhor como

\footnotetext{
* Doutoranda em Filosofia pela Universidade Federal do Rio Grande do Sul. Endereço eletrônico: daniela.gt@, terra.com.br.

** Doutor em Economia pela Universidade Federal do Rio Grande do Sul. É professor do Programa de Pós-Graduação em Economia da Universidade Federal do Rio Grande do Sul. Endereço eletrônico: sabino@ppge.ufrgs. br.

1 Alusão ao personagem bobo e atrapalhado Homer Simpson.

2 Até o momento sem tradução para o português.
} 
funciona um nudge. O primeiro exemplo, intitulado Cafeteria, descreve um resultado empírico que mostra que as pessoas tendem sempre a escolher o que aparece primeiro em uma lista. Dessa forma, se colocarmos a opção frutas no topo do cardápio de uma cafeteria de escola e a barra de chocolate na parte mais inferior, nós estaremos "empurrando gentilmente" ${ }^{3}$ as decisões das pessoas na direção de uma dieta mais saudável, sem com isso limitar as suas escolhas de optar por um chocolate.

O segundo exemplo, intitulado Poupe Mais Amanhã, oferece uma aplicação de outros dois resultados empíricos acerca do processo de tomada de decisão humano: o "efeito posse" e o "efeito desconto". Uma combinação desses dois efeitos sobre as decisões dos indivíduos faz com que as pessoas estejam inclinadas a se comprometer com um plano de poupança que envolva o dinheiro a ser recebido em futuros aumentos de salário do que em aumentos já recebidos. Planos de poupança com uma arquitetura de escolha análoga ao exemplo "Poupe Mais Amanhã” são capazes de induzir os indivíduos a aumentar seus fundos de pensão.

Mesmo não sendo um tema da agenda de pesquisa no Brasil, não é difícil imaginar aplicações importantes do nudge no nosso ambiente econômico. Os desenhos de programas sociais, por exemplo, poderiam ter seus custos reduzidos e sua efetividade aumentada, se a oferta dos auxílios viesse acompanhada de opções reais de saída do programa que respeitassem a lógica do mercado de trabalho e as vicissitudes individuais, fugindo, dessa forma, de uma visão assistencialista e estado-dependente.

Outro exemplo notório de alcance do nudge para o conjunto da sociedade seria a definição de marco regulatório em áreas com forte apelo social, como o consumo de bebidas alcoólicas e acidentes de trânsito ou mesmo a regulação de propagandas envolvendo bebidas, esportes, jovens e celebridades. Em ambos os casos, o alcance social de, por exemplo, tornar efetiva a fiscalização sobre o consumo de álcool ao dirigir, introduzindo protocolos que respeitem a liberdade de escolha, mas que sejam efetivos no acesso à informação privada de quanto o motorista consumiu de álcool, poderia reduzir acidentes e aumentar o dinamismo econômico sem a necessidade de grandes investimentos. Ainda, existem inúmeras outras situações de nudges importantes na questão ambiental ou no desenho de bons protocolos na saúde ou de regras claras no direito, que também poderiam ser pensadas na mesma linha.

Os impactos dessa e de outras situações da nova opção de política pública são notáveis. Assim, nudge tem se mostrado capaz de aproximar visões outrora conflitantes entre políticos de espectros ideológicos distintos (CHAKRABORTTY, 2008). Nesse contexto, esse artigo

3 Essa é a tradução literal de nudging, e serve para ilustrar melhor a natureza desse tipo de arquitetura de escolha. 4 Esses efeitos serão explicados mais adiante nesse trabalho. 
apresenta uma breve introdução à discussão sobre essa nova alternativa de desenhar políticas públicas, no intuito de melhor compreender a sua natureza e de apontar as suas possíveis aplicações. Por fim, comentamos rapidamente algumas de suas implicações éticas.

\section{O QUE É UM NUDGE?}

Nudge é originalmente definido como "qualquer aspecto da arquitetura de escolha que altere o comportamento dos indivíduos de maneira previsível sem limitar o número de opções abertas ou distorcer significativamente os incentivos econômicos" (THALER e SUNSTEIN, p. 6, 2009). Essa definição pode ser refinada para que possamos entender melhor a natureza desse tipo de política pública. O caminho aqui escolhido para abordar esse refinamento é retornar à teoria que deu origem à ideia de nudge, para então compreendê-lo à luz dos seus conceitos.

A teoria que fornece o subsídio teórico-empírico para essa inovação no desenho de políticas públicas é conhecida na literatura como "Heurísticas e Vieses" e foi desenvolvida a partir do trabalho seminal de Tversky e Kahneman sobre decisões sob incerteza ${ }^{5}$. A partir dessa teoria surgiu outra, que procura explicar como o cérebro humano incorre nos comportamentos descritos pelas heurísticas e pelos vieses de escolha, a "Teoria do Processo Dual”. Nessa seção, exporemos em linhas gerais as principais intuições dessas duas teorias para então, em seguida, redefinir nudge em termos de seus conceitos. O objetivo é tornar mais clara a sua natureza, aprofundando assim a nossa compreensão do seu alcance e das suas implicações.

\subsection{HEURÍSTICAS E VIESES}

Como sabemos dos avanços da neurociência, nosso cérebro possui uma capacidade imensa para processar informações e para resolver problemas; contudo, essa capacidade é limitada e/ou sujeita a cometer enganos. Existe um limite de informações que nós podemos processar; o que significa dizer que não fomos projetados para escrutinar de forma eficiente e efetiva os prós e os contras de cada pequena decisão que tomamos diariamente (ex.: devo escovar os dentes durante três ou cinco minutos?). Porém, a urdidura do nosso cérebro desenvolveu atalhos que nos possibilitam tomar decisões rapidamente e de forma bastante razoável em uma grande variedade de assuntos. Esses atalhos são o que os pesquisadores denominam "heurísticas"; caminhos que nosso cérebro utiliza por, na maioria das vezes, gerarem resultados bastante

5 Binmore (2009) discute aspectos importantes da escolha sob incerteza tanto a partir da abordagem das preferências reveladas como da abordagem de utilidade esperada de Von Neumann e Morgenstern, e o paradigma dominante da racionalidade bayesiana para situações de risco ou probabilidade objetiva. Contudo, seguindo Savage, propõe uma nova abordagem que funcionaria para o mundo "grande" de incerteza sem possibilidade de definir probabilidades. De certa forma, a abordagem de nudge é um braço dessa linha de pesquisa. 
satisfatórios que nos ajudam a sobreviver às milhares de decisões que tomamos diariamente muitas vezes sem nos apercebermos.

Entretanto, as heurísticas nem sempre funcionam como deveriam, e algumas vezes dão origem à ocorrência de erros sistemáticos no nosso processo de escolha; a esses erros os pesquisadores denominam "vieses". O ponto central não é que nós, humanos, cometemos erros de vez em quando; mas sim que nós cometemos erros baseados nos atalhos que nosso cérebro desenvolveu para que possamos lidar com a infinidade de decisões que precisamos tomar. Dessa forma, esses erros não apresentam um caráter errático, mas sim uma natureza também sistemática que nos abre a possibilidade excepcional de previsão da falibilidade humana e a possibilidade de minimizar, até certo ponto, esses equívocos.

Para explicar esse aspecto sistemático dos erros humanos, Thaler e Sunstein (2009) lançam mão da Teoria do Processo Dual, baseando a idéia de nudge nos seus conceitos básicos. $\mathrm{Na}$ próxima subseção, elucidaremos as principais intuições dessa teoria e, por fim, estaremos aptos a propor uma definição mais precisa do que constitui um nudge.

\subsection{TEORIA DO PROCESSO DUAL}

A pesquisa recente em psicologia desenvolveu uma abordagem sobre como fazemos escolhas, baseada em dois sistemas, ou seja, uma explicação sobre a maneira como a nossa mente trabalha quando agimos ${ }^{6}$.

Apesar das divergências encontradas na literatura sobre a melhor terminologia, é possível, sem perda relevante de informação, nomear esses dois sistemas como Sistema Automático (SA) e Sistema Reflexivo (SR). O sistema automático é intuitivo, no sentido de que não envolve o que usualmente entendemos como "pensamento", está associado com as partes mais recônditas e primitivas do cérebro (partes que compartilhamos com outras espécies), é não controlável, livre de esforço, associativo, rápido, inconsciente e habilidoso. Por outro lado, o sistema reflexivo é racional e reflexivo, deliberador e autoconsciente, dedutivo, esforço-efetivo, lento, consciencioso e seguidor de regras.

Kahneman (2003) associa o SA com a intuição e o SR com o raciocínio. Ele também entende os dois sistemas em linhas similares ao explicado acima, considerando a intuição como espontânea e livre de esforço e o raciocínio como pensamento racional complexo e, por conseguinte, como altamente esforço demandante. Kahneman (2003) explica a relação entre esses dois sistemas nas seguintes bases: o sistema reflexivo, de certa forma, ensina ao sistema automático como realizar suas tarefas e como monitorar sua performance. Por sua vez, o sistema

6 Uma boa introdução sobre esse tema encontra-se em Kahneman (2003). 
automático seria o responsável pela maioria de nossos pensamentos e ações - mesmo que não sejamos capazes ou não desejemos admitir.

Para melhor entender essa relação "ensino e aprendizagem” entre o SA e o SR, é interessante pensarmos sobre como realizamos nossas tarefas diárias. Normalmente, temos que realizar inúmeras atividades, como escovar os dentes, dirigir, escolher o que e onde comer, sem mencionar as inúmeras coisas que fazemos no trabalho. Quando aprendemos a dirigir, por exemplo, o processo, normalmente, é vagaroso e arrastado no começo, pois temos que prestar atenção em cada detalhe mínimo, contudo, com o passar do tempo, passamos a dirigir sem nem mesmo prestar atenção no que estamos fazendo. Isso ocorreria porque inicialmente usamos o nosso SR para aprender dirigir. Uma vez que o SR apreende e domina, depois de repetições sucessivas, todas as etapas e rotinas "seriam" delegadas ao SA que assumiria a realização daquela tarefa, liberando, assim, o SR para pensar em tarefas novas e mais elaboradas ou difíceis.

Porém, cabe destacar, isso não significa que o SR pode "ensinar"” ao SA a realizar todos os tipos de tarefas. Ou seja, sempre precisaremos do SR, seja para resolver problemas diferentes e novos, seja para refletir e ponderar sobre um determinado assunto ou problema mais complexo. A ideia é que quando somos expostos a tarefas repetidas o SR, inicialmente, aprende a executá-la e, com a prática, "ensina” ao SA que passa a realizar a tarefa.

Psicólogos e neurocientistas argumentam que possuímos esse sistema dual porque a parte mais desenvolvida do nosso cérebro, o neocortex, não é capaz de realizar todas as atividades que nos são exigidas diariamente. Assim, tendemos a usar o SR apenas quando somos confrontados com problemas que exigem raciocínio ativo. Ainda, Kahneman (2003) afirma que o SR também monitora as ações do SA corrigindo as suas decisões sempre que possível.

Kahneman e Frederick (2002) descrevem esse processo de monitoramento da seguinte forma:

"O Sistema 1, de uma forma rápida e intuitiva, propõe respostas para os
problemas de julgamento à medida que eles surgem e o Sistema 2 monitora
a qualidade destas respostas propostas, aprovando-as, corrigindo-as ou subs-
tituindo-as"(p. 51), ressaltando, porém, que " erros e distorções só ocorrem
quando os sistemas falham" (p. 52).

Contudo, o monitoramento que o SR executa usualmente se perde, o que, consequentemente, possibilita a ocorrência de muitos erros de julgamento pelo SA que são expressos nas ações humanas (as ações de tipo Homer). Ellen J. Langer (1992) refere-se a esses erros de julga-

7 A ideia de heurística surge exatamente por essa analogia com o ensino e com a aprendizagem; obviamente, esses atalhos heurísticos são boas metáforas para descrever o processo de tomada de decisões no cérebro.

8 Note que eles se referem ao sistema 2 como o SR e ao sistema 1 como o SA. 
mento como "mindless behavior". Ainda, quando esses "erros" são cometidos, Kahneman (2003) enfatiza que essa seria uma situação na qual a intuição realiza uma performance pobre.

\subsection{UMA DEFINIÇÃO DE NUDGE}

No nosso estágio atual de conhecimento, sabemos como esses vieses funcionam e que eles são sistemáticos. Por conseguinte, podemos prever sob que condições ou circunstâncias eles são mais prováveis de ocorrer. Dessa forma, hipoteticamente, seriamos capazes de influenciar o comportamento das pessoas para mudar aquelas circunstancias - é essa exatamente a ideia ou princípio da arquitetura de escolhas. E é sobre isso que o nudge atua, mudar as circunstâncias na qual as pessoas encontram-se quando da tomada de decisões com o propósito de influenciar seus comportamentos em alguma direção desejada.

Por exemplo, quando escolhemos comer o primeiro item mostrado num cardápio de uma cafeteria, seja ele um chocolate ou uma fruta, estamos pensando de forma não reflexiva sobre o que deveríamos comer e, normalmente, não estamos usando o SR nesse tipo de escolha. A lógica subjacente à necessidade de um nudge, nesses casos, é que temos reconhecidamente uma heurística de sempre escolher o que é mostrado primeiro em um menu. Há um viés associado a essa heurística, qual seja, que por vezes nos rendemos à tentação. Portanto, quando colocamos em primeiro lugar algum alimento em uma lista de menu, nós estamos induzindo a ocorrência do viés de enquadramento (framing bias ${ }^{9}$ ). Consequentemente, estaríamos confiando em julgamentos intuitivos que as pessoas fazem e com os quais elas não estão profundamente comprometidas. (KAHNEMAN; FREDERICK, p.59, 2002).

Entretanto, Sloman (2002) aponta que algumas manipulações na estrutura de escolha são capazes de reduzir alguns vieses, isto é, "uma manipulação que reduz o viés tornando, por exemplo, transparentes uma extensão probabilística ou uma relação lógica estaria, em essência, propiciando uma representação do problema de decisão que permitiria inferências mais objetivas, baseadas em regras, possibilitando assim que as pessoas consigam ir além do raciocínio associativo.” (SLOMAN, p. 380, 2002). Destarte, nudges desse tipo induziriam o uso do SR, em vez de simplesmente objetivar superá-lo.

Agora somos capazes de entender o que é um nudge a partir de uma perspectiva cognitiva. Um nudge é qualquer aspecto da arquitetura de escolha destinada a: 1) ou disparar o uso do SA induzindo-o a incorrer em um específico viés conhecido, superando o monitoramento do SR, portanto escolhendo na direção que supostamente seria aprovada pelo SR; 2) ou reduzir

9 Em vários momentos a tradução literal de termos dessa literatura não é completamente informativa, dai porque usaremos também a expressão original em inglês.

106 
a ocorrência de algum viés específico conhecido ao tornar uma informação particular aparente ou visível na estrutura de escolha. Portanto, induzindo o uso do $\mathrm{SR}^{10}$.

Thaler e Sunstein (2009) observam, por sua vez, que a definição é restrita pelo que chamaríamos de uma regra libertária: "sem esquecer qualquer opção ou sem mudar significativamente seus incentivos econômicos". Essa definição restrita pela regra libertária aplica-se à maioria dos tipos de nudge discutidos na literatura.

Contudo, existem alguns tipos de nudges que não parecem compatíveis com a definição apresentada aqui - os nudges emocionais. Um exemplo óbvio de nudge emocional é a marca (emoticon) feliz ou infeliz mostradas, como experimento, nas contas de energia de algumas famílias (THALER; SUNSTEIN, p. 75, 2009) - o resultado empírico é que indivíduos que recebem o selo infeliz diminuem significativamente seu consumo de energia.

Esse tipo de nudge emocional não está claramente relacionado com a aplicação de qualquer heurística cognitiva pelo SA, nem mostra informação desconhecida ou esquecida pelo indivíduo que induziria o uso do SR. O que estaria atuando aqui seria algum tipo de mecanismo psicológico que influenciaria nossas ações induzindo uma resposta emocional. Se considerarmos essa resposta emocional como sendo parte do trabalho do SA, então esse nudge estaria em congruência com a primeira parte da definição. Todavia, isso não é um consenso na literatura, e, portanto, trataremos esses nudges emocionais de uma maneira separada, mais similar ao mecanismo utilizado pela indústria publicitária - um mecanismo que superaria o uso de nossos meios cognitivos para influenciar nosso comportamento.

Sumarizando entendemos nudge sob três diferentes formas: uma cujo objetivo é superar o uso do SR, uma que induz o seu uso e outra que aciona uma resposta emocional.

\section{MAPEAMENTO DOS TIPOS DE NUDGE E SUAS POSSÍVEIS APLICAÇÕES}

Nessa seção tentaremos explicar as razões pelas quais poderemos ser suscetíveis a um nudge. Inicialmente caracterizaremos os tipos de agencia que nos tornam suscetíveis ao nudge, em seguida, analisaremos a relação dessas agencias com os tipos de erros que sistematicamente incorremos e os tipos de nudges que podem ser associados a eles. Isso nos fornece um mapa geral dos tipos de nudge que existem e de suas possíveis aplicações.

Podemos identificar quatro tipos gerais de agências que podem ser foco de nudges - a Tabela 1 a seguir apresenta um resumo desse tópico. Examinaremos, a seguir, uma por uma.

10 Exemplos desses dois tipos de nudge serão ilustrados abaixo. 
TABELA 1 - TIPOS DE AGÊNCIAS QUE PODEM SER FOCO DE NUDGE

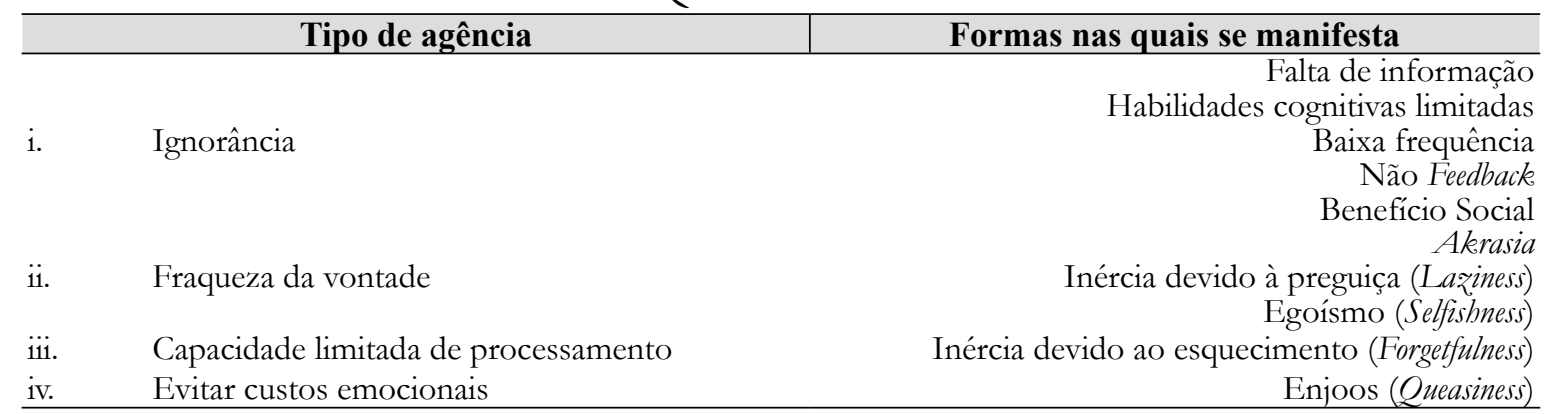

FONTE: Elaboração própria.

i. Ignorância: entendemos 'ignorância' como todos os vieses nos quais incorremos devido à falta de conhecimento. A ignorância pode aparecer de cinco formas distintas: falta de informação, habilidades cognitivas limitadas, baixa frequência, ausência de feedback e benefícios sociais. No caso de falta de informação, podemos ser nudge em alguma direção porque não possuímos todas as informações necessárias para sermos completamente capazes de fazer a escolha. Essa categoria é análoga ao que, na tipologia de Thaler e Sunstein, é conhecido como informação incompleta. Já para o caso de habilidades cognitivas limitadas podemos ser nudged porque, em uma situação qualquer, não entendemos a opção com a qual estamos lidando. Isso acontece quando estamos diante de situações complexas de tomada de decisão nas quais conhecimentos técnicos são necessários. Essa categoria envolve a noção de falta de entendimento das opções capturadas por Wilkinson e Bovens (2009). Na presença de baixa frequência e feedback podemos ser nudged porque estaríamos diante de escolhas que, ou tomamos poucas vezes na vida, ou que não obtivemos feedback depois de realizar escolhas. Em ambos os casos, não temos oportunidade de aprender com os nossos gostos e com as consequências das opções com as quais estamos lidando. Essa categoria contemplaria a ideia de exceção definida por Bovens (2009). Nessas situações, devido à natureza da falta de conhecimento, não podemos realizar inferências estatísticas claras sobre as opções. Como destaca também Bovens (2009), esse pode ser o caso da exceção para obtenção de regra estatística ${ }^{11}$ e isso explicaria por que um nudge deveria ser capaz de permitir que os indivíduos possam escolher por sua melhor opção. Por fim, para os casos de benefícios sociais podemos ser nudged porque somos ignorantes sobre as consequências benéficas, para toda a sociedade, de algumas opções disponíveis. Como enfatizado por Bovens (2009), pode

11 Algo na linha de incerteza knigthiana que justificaria modelos alternativos de racionalidade que superam o modelo bayesiano (Binmore, 2009). 
ocorrer que o benefício social entre em conflito com os interesses individuais perseguidos. Novamente, um nudge deve ser libertário o suficiente para permitir que as pessoas façam suas próprias escolhas.

ii. Fraqueza da vontade: o segundo tipo de agência é caracterizado como defeitos da vontade (Defects of the Will); o que significaria que todos os vieses nos quais incorremos seriam devidos a nossa inabilidade para agir de acordo com as nossas conclusões deliberativas ou racionais. Ou seja, quando sob reflexão racional obteríamos um conjunto de preferências, mas quando realizando a ação livremente revelaríamos um conjunto diferente de preferências. Os Defeitos da Vontade podem aparecer sob três diferentes formas: akrasia, inércia devido à preguiça, e egoísmo. Quando a fraqueza de vontade ocorre na forma de akrasia ${ }^{12}$ estamos sujeitos a um nudge por causa da nossa falta de autocontrole. Tendemos a sucumbir à tentação, optando por alternativas que satisfazem nossas preferências de curto prazo, mas que são contrarias aos nossos interesses de longo prazo. Essa categoria foi capturada por todos os autores relevantes - Bovens; Wilkinson and Thaler; Sunstein. Na presença da inércia devido à preguiça devemos ser nudged devido à nossa tendência à procrastinação quando estamos diante de opções que exigem esforço para serem realizadas ou entendidas. Por exemplo, muitas vezes somos descuidados ao ler contratos ou regras sobre planos de poupança, aluguel ou compra a prazo, etc. (BOVENS, 2009). Na presença de egoísmo devemos ser nudged porque mesmo quando sabemos as consequências e os benefícios sociais de algum curso de ação podemos optar, devido ao egoísmo, por algum curso de ação não interessante socialmente (BOVENS, 2009).

iii. Limitada capacidade de processamento: a terceira fonte de nossa suscetibilidade à nudge é a nossa limitada capacidade de processamento, ou seja, os vieses que podemos incorrer dado que não seriamos capazes de processar todo o conjunto de informações disponíveis. Esse tipo de agência apareceria sob uma única forma: inércia devido ao esquecimento. $\mathrm{Na}$ presença da inércia devido ao esquecimento podemos ser nudged porque somos ou estamos muito ocupados para prestar atenção a tudo e, consequentemente, podemos esquecer algumas das escolhas que necessitamos realizar, ou podemos esquecer alguma informação relevante para tomada de decisão que estamos fazendo. Essa noção é fortemente ligada à ideia de que os seres humanos têm habilidades cognitivas limitadas, não possuindo, portanto, capacidade

12 Expressão grega que significa literalmente não ter controle sobre si mesmo. 
cerebral para lidar com um número infinito de demandas - como elucidado por Thaler e Sunstein.

iv. Evitar custos emocionais: o quarto e último tipo de agência é evitar custos emocionais, significando todos os vieses que incorremos em todas as circunstancias que desejamos evitar fazer escolhas que tem um significativo custo emocional para nós. A forma única dessa agência é o enjoo (Queasiness) ${ }^{13}$. Nesses casos devemos ser nudged porque associamos um elevado custo emocional a alguns tipos de escolhas e, para evitar esses custos, nós "escolheríamos não escolher".

\subsection{RELAÇÃO ENTRE TIPOS DE AGÊNCIA E VIESES}

Depois de caracterizar os tipos de circunstâncias que nos tornam suscetíveis à necessidade de nudge, analisaremos a sua relação com os tipos de erros que costumamos cometer sistematicamente e os tipos de nudges associados a esses erros. Inicialmente, definiremos brevemente os vieses que cometemos em cada caso, a Tabela 2, a seguir apresenta um resumo dos principais pontos desse tópico.

TABELA 2 - TIPOS DE VIESES E ERROS MAIS FREQUENTES QUE COMETEMOS

\begin{tabular}{|c|c|}
\hline Tipos de vieses & \begin{tabular}{|l} 
Erros mais comuns \\
\end{tabular} \\
\hline Ilusão de validade & $\begin{array}{r}\text { Pessoas são excessivamente confiantes em seus próprios } \\
\text { julgamentos mesmo quando há evidências de que seus } \\
\text { julgamentos estão errados. }\end{array}$ \\
\hline Viés de ancoragem (dependência der referências) & $\begin{array}{l}\text { Quando pessoas são expostas a uma referência ou a um } \\
\text { número referência, seus julgamentos são influenciados } \\
\text { por aquele número, caso eles desejem ou não aquela } \\
\text { influência. }\end{array}$ \\
\hline Viés de Status quo (default) & $\begin{array}{r}\text { Pessoas normalmente não se preocupam em abandonar } \\
\text { a regra padrão. }\end{array}$ \\
\hline Efeito dotação & $\begin{array}{r}\text { Pessoas tendem a sobrevalorizar coisas que elas já } \\
\text { possuem ou que formam o seu conjunto de dotações } \\
\text { disponíveis. }\end{array}$ \\
\hline Efeito enquadramento & $\begin{array}{l}\text { A opção de escolha das pessoas depende do conjunto } \\
\text { de opções que fazem parte do processo de escolha. }\end{array}$ \\
\hline Vies de projeção & $\begin{array}{l}\text { Pessoas tendem a projetar seu estado emocional corren- } \\
\text { te no futuro. }\end{array}$ \\
\hline Representatividade & $\begin{array}{l}\text { Pessoas tendem a construir estereótipos que podem não } \\
\text { ser válidos quando similaridade e frequência divergem. } \\
\text { As pessoas tendem a ser mais conscientes sobre os }\end{array}$ \\
\hline Disponibilidade & $\begin{array}{r}\text { riscos prontamente disponíveis, conduzindo a uma } \\
\text { avaliação tendenciosa dos riscos. }\end{array}$ \\
\hline Beneficios agora, custos depois & $\begin{array}{r}\text { Pessoas tendem a buscar benefícios presentes e a evitar } \\
\text { custos presentes. }\end{array}$ \\
\hline Seguir o rebanho & $\begin{array}{r}\text { Pessoas tendem a se comportar de acordo com o } \\
\text { comportamento dos outros. }\end{array}$ \\
\hline
\end{tabular}

FONTE: Elaboração própria de Thaler e Sunstein (2009).

A partir de agora podemos relacionar esses vieses com os tipos de agência definidos na seção precedente, e, sempre que possível, apresentaremos exemplos de nudges relacionados e

13 Bovens (2009). 
factíveis. Novamente, usamos a Tabela 3 abaixo para sintetizar as principais relações entre os tipos de vieses e os erros que incorremos ${ }^{14}$.

TABELA 3 - TIPOS DE AGÊNCIA E VIESES MAIS COMUNS

\begin{tabular}{lr}
\hline \multicolumn{1}{c|}{ Tipos de agência } & Vieses cognitivos \\
i. Ignorância & Ancoragem \\
& Status quo \\
& Enquadramento \\
& Seguir o rebanho \\
Disponibilidade \\
Representatividade \\
Ilusão de validade \\
Víes de projeção \\
Ancoragem \\
ii. Falhas da vontade & Status Quo \\
& Enquadrametno \\
& Seguir o rebanho \\
& Efeito dotação \\
iii. Limitada capacidade de processamento & Ancoragem \\
& Status Quo \\
& Diponibilidade \\
iv. Evitar custos emocionais & Enquadramento \\
& Seguir o rebanho \\
\hline
\end{tabular}

FONTE: Elaboração própria.

i. Ignorância: como já discutido anteriormente, nossa ignorância pode aparecer sob cinco maneiras diferentes. Imagine uma situação na qual dispomos de diferentes opções de planos de saúde ou de poupança que teremos que escolher ou tomar decisões. Nesse caso, é comum não conseguirmos dispor de toda a informação necessária, ou, mesmo possuindo toda informação, podemos não ser capazes de processá-las adequadamente, o que, em ambos os casos demandaria a presença de conhecimentos técnicos que também não dispomos. Nesse casso, poderíamos ser nudged facilmente, através de uma arquitetura amigável das opções de default. Outro exemplo, suponha que tenhamos que decidir sobre realizar ou não um exame preventivo de câncer de próstata. Mesmo sendo sabedores de que a probabilidade de vir a ter câncer de próstata é muito elevada, de $3 \mathrm{em} 10^{15}$, como não conhecemos alguém próximo que tenha contraído esse tipo de câncer, nossa tendência é subestimar esse risco e avaliarmos erradamente a necessidade do exame. Nesses casos, tornar as informações disponíveis pode nos influenciar na direção do risco real e, consequentemente, pode nos ajudar a tomar a decisão correta de realizar o exame. Aqui a estrutura de escolha poderia ser semelhante ao efeito enquadramento e a

14 A maioria dos exemplos apresentados aqui baseiam-se em Thaler; Sunstein (2009).

15 Essa é uma probabilidade hipotética usada apenas para ilustrar o erro de decisão. 
maneira como as probabilidades são apresentadas seriam uma forma de nudge. Podemos, por outro lado, ter que escolher sobre questões que temos que decidir apenas uma vez na vida (baixa frequência e não feedback), como por exemplo, tomar a decisão de realizar ou não uma cirurgia de troca de sexo ou de realizar uma cirurgia de redução de estômago para casos de obesidade mórbida. Nesses casos, novamente, tornar as informações relevantes disponíveis, inclusive sobre as consequências e sobre as opções alternativas de tratamento e de custos e riscos envolvidos nesses tipos de escolha, pode nos ajudar a tomar decisões mais apropriadas e na direção correta. Aqui, também funcionaria mostrar ou disponibilizar informações sobre as decisões da maioria das pessoas em circunstâncias idênticas, ou ajustar a maneira como as probabilidades são apresentadas para torná-las de fácil compreensão, todos esses são exemplos de nudges possíveis e relevantes. Finalmente, podemos ser ignorantes sobre os efeitos ou externalidades negativas de usar embalagens de plásticos em supermercados ou arremessar baterias de celulares nos bueiros e/ou no lençol freático de um centro urbano, etc. Novamente, tornar as informações sobre as consequências negativas dessas ações disponíveis e de fácil acesso ao maior número de pessoas é um exemplo de nudge que auxilia as pessoas a reverem seus hábitos e tomar decisões com efeitos sociais mais positivos par a todos.

ii. Falhas da vontade: essas fraquezas podem aparecer sob três formas distintas. Um caso clássico já abordado aqui é a distribuição das opções de cardápio ou a disposição de alimentos numa vitrine de uma lanchonete que podem ser decisivos na nossa escolha entre fruta e chocolates, ou seja, a arquitetura de escolha pode ser decisiva na definição da qualidade do nosso padrão alimentar. Podemos ser nudged, nessas situações, para sermos capazes de superar nossa akrasia simplesmente enquadrando o menu de tal forma que o mesmo apresente frutas no topo das opções disponíveis. Já no contexto de "poupe mais amanhã" nosso desejo de gastar toda a nossa renda hoje pode ser superado com o nudge que dispara tanto o viés efeito dotação como o viés "benefícios agora, custos depois". Outro exemplo seria o de um nudge que consiga atuar nas opções de default do nosso plano anual de poupança na seguinte linha de ação "o mesmo do ano passado", o que minimizaria a nossa tendência a ter preguiça de ler e preencher contratos e informações de forma elucidativa.

iii. Limitada capacidade de processamento: o terceiro tipo de agência é a limitada capacidade de processamento, que apresenta como principais vieses cognitivos anco- 
ragem, enquadramento, seguir o rebanho, disponibilidade (Tabela 3). Esse tipo de agência pode aparecer sob uma única forma. Imagine que nós não lemos a íntegra das regras sobre a revisão de nosso plano de saúde, e não fazemos isso não por preguiça, mas porque nosso cérebro encontra-se sobrecarregado com outras atividades o que nos leva simplesmente a esquecer de ler o nosso contrato com a instituição seguradora. Nessas situações, dispor de uma configuração padrão adequada pode ser um nudge bastante útil e apropriado. Outro exemplo de uma situação na qual comumente cometemos erros devido, basicamente, ao esquecimento é o de olhar para o lado errado numa esquina de trânsito em uma cidade qualquer, ou até mesmo o erro de não olhar para lado algum, e aumentar, assim, a probabilidade de sinistros. Nessas situações, possibilitar o enquadramento de nossas escolhas, com uma placa destacando um apelo simples como "olhe a direita" pode ser um aviso útil e que, novamente, diminui o risco de acidentes no transito.

iv. Evitar custos emocionais: o quarto e último tipo de agência é a tendência que temos a evitar custos emocionais o que, normalmente, nos leva a evitar ter que escolher, adiando ou evitando tomada de decisões importantes. Nesses casos os principais vieses cognitivos são status quo, enquadramento e seguir o rebanho (Tabela 3). Esse tipo de agência também só aparece sob uma única forma. A situação mais comum diz respeito a tomar decisão que envolva um elevado custo emocional, como decidir se realiza ou não uma doação de rins para um parente ou, mesmo, se doa um órgão para um desconhecido. Nesses casos podemos, devido a nossa tendência a evitar custos emocionais, simplesmente não tomar decisão alguma, "escolher não escolher" para evitar o elevado custo emocional envolvido. Novamente aqui, uma configuração adequada do conjunto de opções pode funcionar como um importante nudge para o tomador de decisão.

\section{CONSIDERAÇÕES FINAIS E IMPLICAÇÕES ÉTICAS}

Por fim, devemos comentar algumas dúvidas e críticas que essa abordagem vem recebendo da literatura recente. Reconhecemos que nudge é a escolha das pessoas, é uma forma de melhorar o bem estar dos que estão em situação de ter que tomar uma decisão, sem, contudo, limitar o seu conjunto disponível de escolhas; e entendemos que realizar o que a literatura chama de paternalismo libertário pode ser uma forma importante e atraente de conduzir políticas públicas para uma solução satisfatória do ponto de vista de ganhos de bem-estar para todos. 
Entretanto, precisamos também reconhecer que ainda cabe analisar de forma mais acurada se essa "terceira via real" é capaz de manter o comprometimento libertário e ao mesmo tempo preservar o princípio da neutralidade na política pública.

No artigo "Paternalismo Libertário não é um oximoro" Sunstein e Thaler (2003) concluem, a partir dos resultados encontrados até agora, que falta às pessoas um conjunto de preferências bem ordenado e que, em muitos casos, o próprio significado pleno de preferências não é muito claro e objetivo. Em "Nudge: Improving Decisions about Health, Wealth and Happiness", os mesmos autores argumentam que preferências existem, mas são inconsistentes. Portanto, seres humanos são dicotômicos e apenas parcialmente planejadores (análogo ao homos economicus) e também são parcialmente executores (análogo ao Homer economicus). "In the morning the inner Planner resolves to forgo dessert at dinner tonight, and then, after dinner, the inner Doer proceeds to devour a bowl of ice cream" (LEONARD, p. 4, 2008).

Assim, se definirmos que preferências não existem formalmente, como devemos decidir em qual direção influenciar a escolha das pessoas - levando em consideração seu melhor interesse próprio? Como resolveremos o problema de identificar preferências empiricamente? Usualmente apelamos ao princípio da preferência revelada para resolvê-lo, porém, se escolhas não revelam preferências individuais porque elas não existem formalmente, de que maneira podemos acessar ou obter informações sobre essas preferências para ter conhecimento das necessidades ou dos autointeresses básicos dos indivíduos que supostamente gostaríamos de ajudar?

De outra forma, se o significado do termo preferências é claro, mas existem inconsistências entre as preferências do planejador e as preferências do executor interno, ainda teríamos um problema em mãos. Como fazer para decidir que preferências, do planejador ou do executor, devem ser privilegiadas de forma a tornar melhor a vida do indivíduo? Leonard (2008) fornece um insight interessante a esse respeito, destacando que o paternalismo libertário toma o lado do planejador e identifica suas preferências com o suposto melhor interesse do indivíduo. A meta do nudge, nesse caso, seria proteger as preferências do planejador das preferências do executor. Homer Simpson levaria a pior nesse debate.

A preocupação básica é a de que Thaler e Sunstein (2009) não conseguem fornecer nenhum conjunto de arrazoados suficientes para por um tipo de preferência como sendo melhor que a outra - por que devemos satisfazer as preferências do planejador e não desejar o que o executor prefere? Wilkinson (2009) também antever um ponto indeterminado deixado por Thaler e Sunstein (2009) em relação ao que se entende por "ser melhor", quando enfatiza que “apontar erros na razão prática não mostra a alguém o que seria o melhor a ser feito ou o que 
seria o mais saudável”(p. 6).

\section{REFERÊNCIAS}

ANNAS, J. The morality of happiness. New York: Oxford University Press, 1993.

BINMORE, K. Rational decisions. Princenton University Press, 2009.

BOVENS. L. The Ethics of Nudge. Forthcoming in Till Grune-Yanoff and S.O. Hansson preference change: approaches from philosophy, economics and psychology. Berlin and New York: Springer, 2009.

CAMERER, C.; ISSACHAROFF, S.; LOEWENSTEIN, G.; O'DONOGHUE, T.; RABIN, M. 'Regulation for Conservatives: Behavioral Economics and the Case for "Asymmetric Paternalism”. University of Pennsylvania Law Review, v. 151, n. 3, p. 1211-1254, 2003.

CAMERER, C. "Behavioural Economics". World congress of the econometric society, London, 2005.

CHAKRABORTTY, A. "From Obama to Cameron, why do so many politicians want a piece of Richard Thaler?”. Guardian, 2008.

DWORKIN, G. Paternalism. Stanford Encyclopaedia of Philosophy. Disponível em: $<$ http://plato.stanford.edu/>. Acesso em: 2005.

FRIEDMAN, M. Capitalism and freedom. University of Chicago Press, 1982.

KAHNEMAN, D. Maps of bounded rationality: psychology for behavioral economics. American Economic Review, 2003.

KANT, I. Groundwork of the metaphysics of morals. In: Gregor, M. J. Cambridge University Press. 1997.

LANGER, E. J. Matters of mind: Mindfulness/mindlessness in perspective. Consciousness and Cognition, v. 1, p. 289-305, 1992.

LEONARD, T. C. Constitutional Political Economy. Springer Netherlands. v. 19, n. 4, . 2008. Resenha.

MILL, J. S. On Liberty. London: Yale University Press, 2003.

SLOMAN, S. Two Systems of Reasoning. In: Heuristics and biases. Cambridge University Press, 2002.

SPIEGEL, A.Using psychology to save you from yourself. Npr, 2009.

SUGDEN, R. Taking unconsidered preferences seriously. Royal Institute of Philosophy Supplement, n. 81, p. 209-232, 2006.

SUNSTEIN, C. R.; THALER, R. H. Libertarian paternalism is not an Oxymoron. University of Chicago Law Review, v. 70, p. 1159-1202, 2003.

TAYLOR, K. Brainwashing: the science of thought control. Oxford University Press, 2006.

THALER, R. H.; SUNSTEIN, C.R. Nudge. London: Penguin Books, 2009.

TVERSKY, A.; KAHNEMAN, D. Judgment under uncertainty: heuristics and biases. Science, New Series, v. 185, n. 4157, p. 1124-1131.

WILKINSON, M. Nudging, health, and making people better off. London, jul. 2009. 
